\title{
Differential outcomes attenuate memory impairments on matching-to-position following pyrithiamine-induced thiamine deficiency in rats
}

\author{
LISA M. SAVAGE \\ Neurology Research Service, VA Medical Center, San Diego, California \\ and \\ PHILIP J. LANGLAIS \\ Neurology Research Service, VA Medical Center, San Diego, California \\ and San Diego State University, San Diego, California
}

\begin{abstract}
Numerous studies have demonstrated that rats with pyrithiamine-induced thiamine deficiency (PTD) have extensive diencephalic damage and are severely impaired at acquiring new tasks that require the use of "working memory." The differential outcomes (DO) procedure, which correlates specific reinforcers with specific discriminative stimuli, improves performance of normal subjects on various conditional discrimination tasks. The present study revealed that, relative to PTD rats' receiving uncorrelated reinforcers, implementing the DO procedure in the T-maze version of matchingto-position completely eliminated the PTD learning deficit. These results suggest that utilizing different information processing systems in brain-damaged subjects may reduce their memory impairments.
\end{abstract}

Pyrithiamine-induced thiamine deficiency (PTD) in the rat has been used to model both the pathological and the behavioral impairments observed in humans with Wernicke-Korsakoff syndrome (WKS) (Langlais, 1992). This treatment (PTD) produces highly consistent, excitotoxic type (Langlais \& Mair, 1990; Langlais \& Zhang, 1993) bilateral lesions of the midline intralaminar, mediodorsal lateral, and posterior thalamic nuclei, as well as the mammillary bodies (Mair, Knoth, Rabchenuk, \& Langlais, 1991; Langlais \& Savage, 1995). The pattern of neuropathological damage produced in this PTD rat model is similar to that found in postmortem brains of patients who suffered from WKS (Harper \& Kril, 1993; Jacobson \& Lishman, 1990; Troncoso, Johnston, Hess, Griffin, \& Price, 1981; Victor, Adams, \& Collins, 1971).

Rats with PTD-induced lesions, like WKS patients (see Jacobson \& Lishman 1987; Parson \& Nixon, 1993), have significantly impaired anterograde memory. In such rats, deficits have been systematically reported on tasks that require the use of "working memory." Rats that have recovered from a bout of PTD display impaired performance on tasks such as delayed alternation (Mair, Anderson, Langlais, \& McEntee, 1985), appetitive (Mair et al.,

This research was supported by a VA Merit Award to P.J.L. The authors would like to thank Angela Bassett and Arthur Sweet for their technical assistance. L. M. Savage is now at the Department of Psychology, SUNY-Binghamton, Binghamton, NY 13902-6000 (e-mail: lsavage@bingsuns.cc.binghamton.edu). Reprint requests should be addressed to P. J. Langlais, Neurology Research Svc (127), Veterans Administration Medical Center, 3350 La Jolla Village Dr., San Diego, CA 92161(e-mail: planglais@popmail.ucsd.edu).
1985) and aversive (Mair, Otto, Knoth, Rabchenuk, \& Langlais, 1991) spatial nonmatching-to-sample (NMTS), radial arm maze (Robinson \& Mair, 1992), and acquisition of both nonmatching-to-position (NMTP) and matchingto-position (MTP) in the T-maze (Langlais \& Savage, 1995).

The differential outcomes (DO) procedure has been shown to enhance performance on matching-to-sample (MTS) tasks and other conditional discriminations (Alling, Nickel, \& Poling, 1991a, 1991b; Demarse \& Urcuioli, 1994; Linwick, Overmier, Peterson, \& Mertens, 1988; Peterson \& Trapold, 1980; Savage, Stanchfield, \& Overmier, 1994; Trapold, 1970; Williams, Butler, \& Overmier, 1990). In the standard laboratory procedure, all correct choices in the MTS task are reinforced with the same outcome (typically food); whereas the DO procedure involves reinforcing each sample stimulus/ correct choice combination with a distinct outcome (Trapold, 1970). For example, one stimulus/choice combination (i.e., tone $\rightarrow$ left lever) leads to the delivery of food at the end of the trial, whereas the alternative combination (i.e., click $\rightarrow$ right lever) results in a different outcome, such as access to water. This procedure allows for the learning of a predictive relation as to which reinforcer will be presented on the basis of the antecedent stimulus conditions. The common control procedure for such an experimental design is to use the same stimuli and reinforcers, but to randomize the relationship between them. Under those conditions, or the standard laboratory procedure, there are no predictive relations about which outcome will be given on the basis of the antecedent stimulus conditions. The effect of using unique 
reinforcers correlated with each correct stimulus-choice alternative, relative to the standard procedure or different but uncorrelated reinforcers, is an increase in speed of acquisition and a higher terminal accuracy (Demarse \& Urcuioli, 1994; Linwick et al., 1988; Williams et al., 1990). This enhancement has been termed the differential outcomes effect (DOE), a robust phenomenon that has been demonstrated with a variety of animal subjects, such as rats, dogs, and pigeons, and with a wide range of reinforcer relationships (see Goeters, Blakely, \& Poling, 1992, for a review).

The DO procedure was first demonstrated to improve acquisition and memory performance in normal rats (Carlson \& Wielkiewicz, 1976; Fedorchak \& Bolles, 1986; Trapold, 1970), but its effect on the performance of braindamaged rats has not been tested. Recently, Savage et al. (1994) found that the DO procedure increased accuracy at long delays, even when pigeons were administered amnestic drugs. Their study suggests that the DO procedure may be used to improve the learning and memory performance of amnestic subjects. In the present study, we implemented the DO procedure in the T-maze to determine whether it would attenuate the acquisition and memory performance deficits previously reported in PTD-treated rats on variations of MTS (Langlais \& Savage, 1995; Mair, Knoth, et al., 1991; Mair, Otto, et al., 1991).

\section{METHOD}

\section{Subjects}

Fifty-two male Sprague-Dawley rats, weighing $250-274 \mathrm{~g}$ at the onset of the study, served as subjects. The animals were matched for weight, marked, housed 2 per cage, and maintained under conditions of constant temperature and humidity on a 12:12 h light:dark cycle (onset of light, 5:00 a.m.).

\section{Treatment}

The animals were first randomly assigned to one of the following treatments: (1) pair-fed control (CT, $N=20$ ), or (2) pyrithiamine-induced thiamine deficiency (PTD, $N=32$ ) groups. Subjects in the PTD group were free-fed a thiamine-deficient chow (Teklad Diets, Madison, WI) and given daily injections $(0.25 \mathrm{mg} / \mathrm{kg}$, i.p.) of pyrithiamine hydrobromide (Sigma, St. Louis). On Days 13-16 of treatment, animals display signs of local tonoclonic movement of the front and hind limbs, and generalized convulsions (seizures). Within 3-5 h after observing the onset of "seizures," PTD-treated animals were given an injection of thiamine $(100 \mathrm{mg} / \mathrm{kg}$, i.p.) every $8 \mathrm{~h}$ until the seizure activity disappeared and the animals regained upright posture. The CT animals were fed an amount of thiamine-deficient chow equivalent to the average amount consumed by the PTD groups on the previous day of treatment and were given daily injections of thiamine $(0.4 \mathrm{mg} / \mathrm{kg}$, i.p.). After treatment, all subjects were placed on regular chow and allowed to regain the weight lost during treatment. After 2 weeks of free-feeding, subjects were reduced to $85 \%$ of their free-feeding weights and maintained by supplementary feedings ( 20 g per day) after each behavioral session.

\footnotetext{
Apparatus

Spatial learning and memory were assessed in a T-maze constructed of Plexiglas that contained two goalboxes, each measuring $42.5 \times 11 \times 14 \mathrm{~cm}$, connected to a central choice area, $22 \times$ $11 \times 14 \mathrm{~cm}$, that was attached perpendicularly to the startbox,
}

$28 \times 11 \times 14 \mathrm{~cm}$. The start- and goalbox arms were covered with separate Plexiglas lids. Manually operated Plexiglas guillotine doors separated the startbox and the two goalboxes from the choice area. The reinforcers, $1 / 2$ of a Kellogg's Froot-Loop or chocolate milk $(0.5 \mathrm{ml})$, were delivered on a tray inserted through a slot in the correct goalbox. The testing environment was dark except for a 20 -W light source positioned 12 in. above the choice area.

\section{Procedure}

Two weeks after recovering from the treatment regime, the subjects were divided into four groups: pyrithiamine-induced thiamine deficiency differential (PTD-DIFF; $N=14$ ), pair-fed differential (PF-DIFF; $N=9$ ), pyrithiamine-induced thiamine deficiency nondifferential (PTD-NONDIFF; $N=14$ ), and pair-fed nondifferential (PF-NONDIFF; $N=11$ ). The subjects were adapted to the T-maze and then trained on an MTP task (Langlais \& Savage, 1995; Thomas \& Spafford, 1984). All sessions contained 12 trials. The goalbox containing the reinforcer was predetermined by using a random schedule (Fellows, 1967). Trials within a session were distributed (i.e., Trial 1 was completed by all animals before Trial 2 was conducted), with an intertrial interval of approximately 4.5 min.

Pretraining. The differential or nondifferential outcomes procedure was implemented from the onset. In the differential groups (DIFF), the subjects were given $1 / 2$ of a Froot-Loop upon entering the left goalbox, and chocolate milk $(0.5 \mathrm{ml})$ upon entering the right goalbox. In the nondifferential groups (NONDIFF), entering either goalbox resulted in the random presentation of one of the two outcomes. Each session included an equal number of trials reinforced with a Froot-Loop or chocolate milk. Initial training consisted of five sessions of goalbox feeding; for each trial, the subjects were placed in a goalbox containing one of the reinforcers for $1 \mathrm{~min}$. Once the subjects ate reliably, they were trained on one-arm runs. During the one-arm runs, the subjects were placed in the startbox for 3-5 sec, the door was then raised and one of the goalbox doors was open. The subjects were allowed to enter the goalbox and receive either chocolate milk or $1 / 2$ of a Froot-Loop. The rats were trained on one-arm runs for five sessions.

Matching-to-position. Each trial of the MTP task consisted of a forced run followed immediately by a choice run. On the forced runs, the subjects were placed in the startbox and the door to the choice area was raised, the subjects then entered the choice area, one arm was blocked, and the other remained open. Once the subjects entered the goalbox that was not blocked, the door was lowered and the reinforcer was inserted to allow the subjects access. As in pretraining, subjects in the DIFF groups were given $1 / 2$ of a Froot-Loop when the sample was "turn left," and chocolate milk $(0.5 \mathrm{ml})$ when the sample was "turn right." Subjects in the NONDIFF groups were given random presentations of the two reinforcers. Once the reinforcer was consumed, the food tray was removed and the subjects were returned to the startbox by the experimenter. To control for odor cues, any remnants of the reinforcer from the previous trail were wiped away and both food trays outside of both goalbox slots were filled with the same reinforcer on each trial. The choice run was then initiated (approximately a 5 -sec interval). Choice runs were identical to forced runs, except that both goalboxes were open. If a subject entered the same goalbox (matching) as on the preceding forced run, the door was lowered and the subject was given the same reinforcer that it received on the forced run. Alternatively, if the subject entered the goalbox opposite to that on the previous forced run (nonmatching), the door was lowered and the subject was confined to the goalbox without reinforcement for $10 \mathrm{sec}$. The intertrial interval was approximately $4.5 \mathrm{~min}$.

Delayed MTP. Once subjects performed at criterion (above $90 \%$ correct) for two sessions, delayed MTP was initiated. The delay intervals were 5, 30, 60, and $90 \mathrm{sec}$. Each session contained an equal 
number of trials at each delay interval, which were randomly distributed within each session. Six sessions of mixed-delay trials were conducted.

\section{Histological Analysis}

Once behavioral testing was concluded, the animals were anesthetized and their brains were removed, post fixed in a $10 \%$ formalin solution for $72 \mathrm{~h}$, and then transferred to a solution containing $30 \%$ sucrose. Frozen coronal sections $(40 \mu \mathrm{m})$ were cut from the level of the anterior commissure to the posterior pontine tegmentum. Sections were stained with cresyl violet, and the degree of pathological damage to diencephalic structures was rated qualitatively as previously described (Langlais, Mandel, \& Mair, 1992; Mair, Otto, et al., 1991): normal = no gross pathology; IML spared = slight gliosis and moderate cell loss restricted to anterior and some portions of the internal medullary lamina (IML) region of the thalamus, and moderate cell loss in mammillary body nuclei; IML lesioned = gliotic scar and tissue loss within the entire region of the IML, extending to the lateral thalamus and present within the anterior, middle, and posterior regions of the thalamus, and severe cell loss in mammillary body nuclei.

Degree of damage to the anterior ventral nucleus of the thalamus (interaural, or IA, $7.2 \mathrm{~mm}$ ) was rated on a scale from 1 (normal, no neuronal loss or gliosis) to 6 (complete neuronal loss and gliosis). All qualitative rating was done independently by two observers (L.S. and P.L.) who were blind to the subjects' identification. There were no discrepancies between the observers' categorization of subjects into the three groups of normal, IML spared, and IML lesioned. However, there were occasional differences in scoring (1-6) the damage to the anterior ventral complex. In these few cases, the average score between the two observers was used.

In addition, the following quantitative measures of thalamic, mammillary body, and cortical loss were obtained for reference to behavioral impairments. The amount of midline thalamic tissue destroyed by PTD was estimated by measuring the interventricular distance at the midline (Langlais \& Savage, 1995; Robinson \& Mair, 1992). This distance was measured (in millimeters) from the floor of the dorsal III ventricle to the roof of the III ventricle at the following approximate IA locations: $6.9 \mathrm{~mm}$ (anterior thalamus); $6.44 \mathrm{~mm}$ (middle thalamus); and $5.60 \mathrm{~mm}$ (posterior thalamus), according to the atlas of Paxinos and Watson (1986). The area (in square millimeters) of the mammillary body complex (at approximately IA $4.8 \mathrm{~mm}$ ) was also measured by tracing its perimeter along the following landmarks: dorsal (the supramammillary nucleus); lateral (the lateral border of the lateral mammillary nucleus); and ventral (the roof of the mammillary recess and cross- ing fibers of the arcuate nucleus). The thickness (in millimeters) of the frontal cortex, parietal cortex (HL1, HL2, Parl) and perirhinal cortex were measured at IA $6.9 \mathrm{~mm}$ as previously described (Langlais \& Savage, 1995). Quantitative measures were determined by the use of video images taken from a Zeiss light microscope using a Sony XC-77 camera, digitized by a Quickcapture framegrabber (Data Translation, Marlboro, MA), and analyzed using an image analyzer program (IMAGE, v.1.43, NIH, Bethesda, $\mathrm{MD)}$ on a Macintosh IIci computer.

\section{Statistical Analysis}

A one-factor analysis of variance (ANOVA) was used to analyze the number of trials to attain criterion for the MTP task as well as all quantitative pathological data. The qualitative score of damage to the anterior ventral complex was examined in a nonparametric analysis (Kruskal-Wallis ANOVA). A one-within and one-between repeated measures ANOVA was used to analyze percent correct data obtained for the delayed trials of MTP. Fisher's LSD procedure was used for follow-up tests of between-group differences if the overall $F$ was significant. For all statistical analyses, significance was accepted at the .05 level.

\section{RESULTS}

\section{Histopathological Findings}

In animals rated as IML spared, the neuronal loss and mild gliosis did not involve tissue loss and was restricted to the following thalamic nuclei: anterior ventral, gelatinosus, and ventral part of the mediodorsal. The mammillary body was not grossly different from that in controls. Rats with severe thalamic lesions and rated as IML lesioned had more widespread tissue loss within the thalamus and mammillary body. As is shown in Figure 1E, in the IML-lesioned brains there was a gliotic scar that was present throughout the entire anterior-posterior length of the thalamus, damaging large portions of midline intralaminar nuclei and internal medullary lamina, and extended to more lateral structures. Additional structures damaged in the IML-lesioned group were the ventrolateral, posterior nuclear group, parafascicular nucleus, and mammillary body.

Of the 32 subjects treated with a bout of PTD, 17 were rated as IML spared (9 DIFF IML spared, 8 NONDIFF

Table 1

Quantitative Measures of the Thalamus, Mammillary Bodies, and Cortex

\begin{tabular}{|c|c|c|c|c|c|c|c|c|c|c|}
\hline \multirow[b]{3}{*}{ Group } & \multicolumn{6}{|c|}{ Thalamic Interventricular Distance } & \multirow{2}{*}{\multicolumn{2}{|c|}{$\begin{array}{c}\text { Area of } \\
\text { Mammillary } \\
\text { Body }\end{array}$}} & \multirow{2}{*}{\multicolumn{2}{|c|}{$\begin{array}{c}\text { Cortex } \\
\text { Thickness } \\
\text { Parietal (HL) } \\
\end{array}$}} \\
\hline & \multicolumn{2}{|c|}{ Anterior } & \multicolumn{2}{|c|}{ Middle } & \multicolumn{2}{|c|}{ Posterior } & & & & \\
\hline & $M$ & $S E$ & $M$ & $S E$ & $M$ & $S E$ & $M$ & $S E$ & $M$ & $S E$ \\
\hline \multicolumn{11}{|l|}{ Control } \\
\hline $\operatorname{DIFF}(N=6)$ & 3.09 & .13 & 3.34 & .07 & 3.35 & .06 & 2.79 & .19 & 1.85 & .03 \\
\hline NONDIFF $(N=7)$ & 3.10 & .10 & 3.41 & .07 & 3.43 & .11 & 2.68 & .12 & 1.87 & .03 \\
\hline \multicolumn{11}{|l|}{ IML Spared } \\
\hline $\operatorname{DIFF}(N=9)$ & 2.99 & .05 & 3.10 & .12 & 3.11 & .12 & 2.35 & .11 & 1.86 & .03 \\
\hline NONDIFF $(N=8)$ & 2.73 & .17 & 3.07 & .13 & 3.20 & .12 & 2.62 & .07 & 1.86 & .06 \\
\hline \multicolumn{11}{|l|}{ IML Lesioned } \\
\hline $\operatorname{DIFF}(N=5)$ & 1.90 & $.09 *$ & 2.30 & $.10^{*}$ & 2.19 & $.15^{*}$ & 1.71 & $.21^{*}$ & 1.68 & .07 \\
\hline NONDIFF $(N=6)$ & 2.09 & $.11^{*}$ & 2.36 & $.11^{*}$ & 2.28 & $.22^{*}$ & 1.78 & $.21^{*}$ & 1.65 & $.06^{*}$ \\
\hline
\end{tabular}

Note-Mean thalamic interventricular distance ( $\pm 1 S E M$, in $\mathrm{mm}$ ) was measured in coronal fixed sections $(40 \mu \mathrm{m})$ from the floor of the dorsal third ventricle to the roof of the third ventricle at approximately interaural (IA) $7.00 \mathrm{~mm}$ (anterior), $6.44 \mathrm{~mm}$ (middle), and $5.60 \mathrm{~mm}$ (posterior). Area (in $\mathrm{mm}^{2}$ ) of the mammillary body complex was measured at IA $4.8 \mathrm{~mm}$. Thickness (in $\mathrm{mm}$ ) of the hindlimb (HL) of the parietal cortex was taken at IA $7.00 \mathrm{~mm}$. *Significant $(p<.05)$ difference from control groups. 
IML spared) and 11 as IML lesioned (5 DIFF IML lesioned, 6 NONDIFF IML lesioned). Four PTD animals did not recover from the treatment and were removed from the study. All 20 pair-fed animals ( 9 DIFF control and 11 NONDIFF control) were classified as normal.

A subset of pair-fed control animals ( $N=6$ DIFF control; $N=7$ NONDIFF control) was used for comparison with quantitative measures of PTD-induced pathological damage of the thalamus, mammillary bodies, and cortical regions. As is shown in Table 1, there was significant tissue loss within the midline region of the thalamus, shown by the reduced interventricular distance in both PTD IML-lesioned groups. At the anterior $[F(5,35)=$ $18.14, p<.0001]$, middle $[F(5,35)=16.30, p<.0001]$, and posterior $[F(5,35)=14.22, p<.0001]$ thalamic levels there were significant group effects. Post hoc analyses (Fisher's LSD), at all three levels, demonstrated that the interventricular distance was significantly smaller in the IML-lesioned groups than in all other groups (all $p s<.001$ ). However, the DIFF IML-lesioned group and the NONDIFF IML-lesioned group were not significantly different from each other (all $p \mathrm{~s}>.28$ ). Furthermore, the DIFF IML-spared group and the NONDIFF IML-spared were also not significantly different from each other or controls at any thalamic level (all $p \mathrm{~s}>.08)$.

A Kruskal-Wallis ANOVA $[H(5)=30.55, p<.0001]$ of the qualitative measurements of the anterior ventral complex revealed significant group differences [control = DIFF, 1.0 (median), 1.0 (mean), 7.0 (rank); NONDIFF, 1.0, 1.0, 7.0; IML spared = DIFF, 4.0, 3.55, 23.17; NONDIFF, 4.0, 3.75, 24.31; IML lesioned = DIFF, 6.0, $6.0,35.00$; NONDIFF, 6.0, 6.0, 32.00]. Between pathological treatment groups, both IML-spared and IMLlesioned groups differed from controls (all $p \mathrm{~s}<.001-$ see Figure 1, panels B, E, H). However, within pathological treatment groups (DIFF and NONDIFF), there were no differences (all $p \mathrm{~s}>.88$ ).

The quantitative analysis of the area of the mammillary bodies also revealed significant group differences $[F(5,35)=9.14, p<.0001]$. As shown in Figure 1 (panels
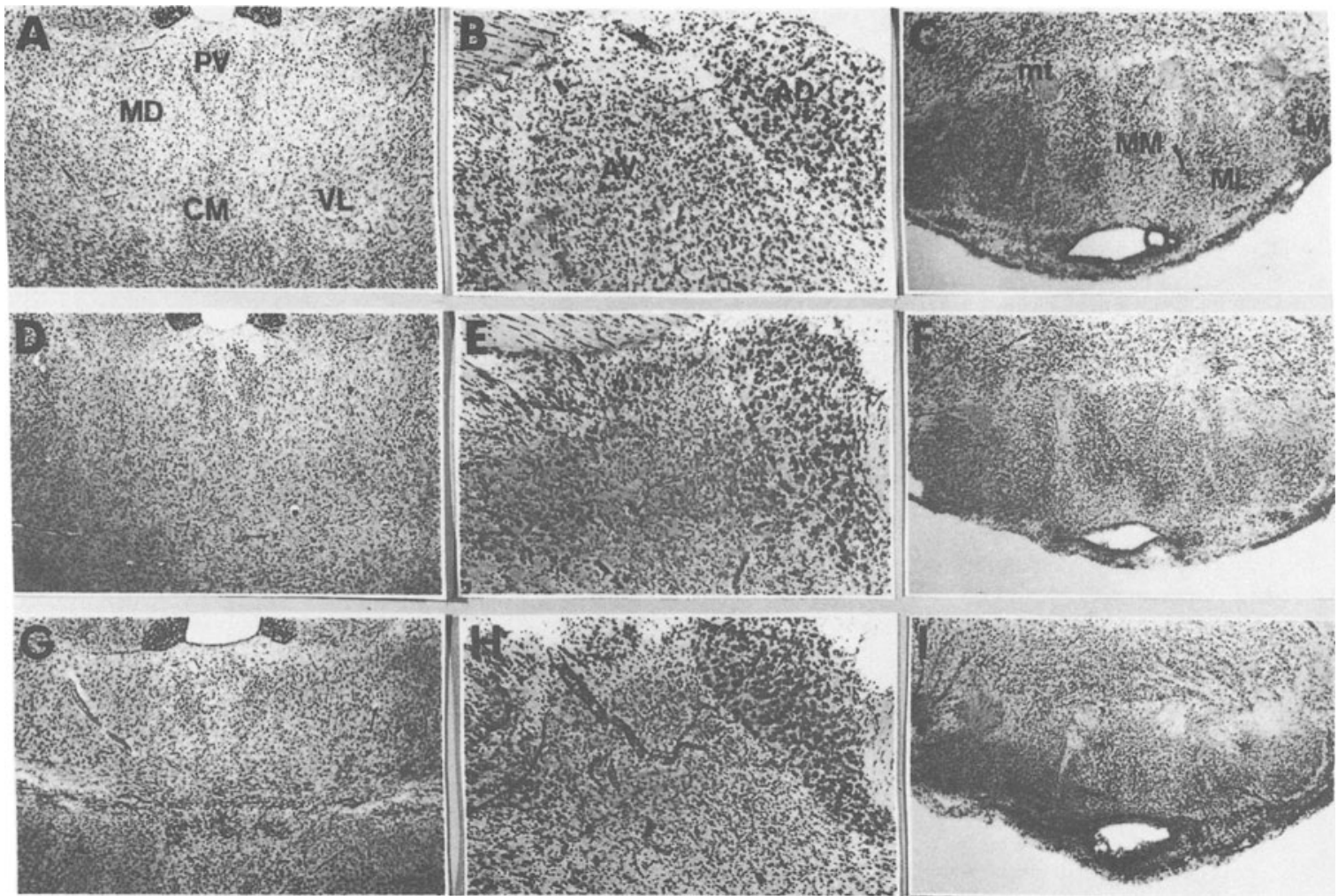

Figure 1. Representative photomicrographs of cresyl-violet-stained coronal sections ( $40 \mu \mathrm{m}$ thick) from a control rat (top row, $A-C)$, a pyrithiamine-treated (PTD) rat with moderate pathological damage that spared most of the internal medullary lamina (IML-spared) (middle row, D-F), and a PTD rat with severe pathological damage throughout the entire internal medullary lamina (IML-lesioned) (bottom row, G-1). The first column represents sections from the mid-thalamus (approximately IA 6.44 mm). Gross pathology, represented by a gliotic scar, is present in only the PTD IML-lesioned rat (G). The second column demonstrates the nearty complete loss of neurons in the dorsomedial and ventrolateral divisions of the anteroventral nucieus and complete preservation of neurons in the anterodorsal nucleus of a PTD IML-lesioned animal $(\mathrm{H})$, and significant reduction of neurons in the dorsomedial and ventrolateral divisions of the anteroventral nucleus of a PTD IML-spared animal (E). The third column shows the mammillary bodies. In the PTD IML-lesioned animal, moderate neuronal loss is evident, and there is marked gliosis (I); no significant differences were observed between the PTD IML-spared (F) and pair-fed (C) animals. Abbreviations: PV, paraventricular nucleus; MD, medial dorsal nucleus; CM, central medial nucleus; VL, ventrolateral nucleus; AV, anteroventral nucleus; AD, anterodorsal nucleus; mt, mammillothalamic tract; MM, medial mammillary nucleus, medial part; ML, medial mammillary nucleus, lateral part; LM, lateral mammillary nucleus. 
C, F, I), the mammillary bodies were markedly shrunken in both the DIFF and the NONDIFF IML-lesioned groups. This shrinkage was confirmed by a significantly smaller total area in the DIFF and NONDIFF IMLlesioned groups (see Table 1) than in the control groups and spared groups (all $p s<.001$ ). The area of mammillary bodies in the DIFF and NONDIFF IML-spared groups did not significantly differ $(p=.15)$, nor did it differ with that of controls $(p=.052)$.

A group effect was also observed in the thickness of the HL region of the parietal cortex $[F(5,35)=4.13, p<$ $.005]$. Further analyses (Fisher's LSD) demonstrated that although not significantly different from one another $(p>.66)$, both the DIFF and NONDIFF PTD IMLlesioned animals had significantly thinner HL1 cortex than that of controls $(p<.03)$ or the other PTD groups (all $p s<.05$ ). There was no significant reduction in HL1 thickness of the DIFF or NONDIFF PTD IML-spared animals $(p>$.97). Measurements of thickness in frontal, perirhinal, occipital, and temporal cortical areas of the PTD animals (data not shown) were not significantly different from those for controls.

\section{Behavioral Findings}

Acquisition of MTP. Analysis of the number of trials to criterion revealed a significant group effect $[F(5,42)=$ $6.73, p<.0001]$. As is shown in Figure $2 \mathrm{~A}$, all three differential groups (DIFF control, DIFF IML-spared, and DIFF IML-lesioned) and the NONDIFF control group did not differ from one another (Fisher's LSD, all $p$ s > .17). Despite comparable brain damage to their DIFF counterparts (i.e., DIFF IML-spared and DIFF IMLlesioned; see the pathological results in Table 1), the NONDIFF IML-spared and the NONDIFF IMLlesioned groups took significantly more trials than did their DIFF counterparts and the DIFF and NONDIFF control groups (Fisher's LSD, all $p$ s $<.01$ ).

Delayed MTS. Once the subjects reached criterion and were tested on delayed MTP, accuracy across the groups was not significantly different $[F(5,42)=1.36, p=.26)$. Figure $2 \mathrm{~B}$ shows that all subjects displayed a significant decrease in performance accuracy as the delay interval increased $[F(3,15)=51.99, p<.0001]$.

\section{DISCUSSION}

This study has demonstrated three important points: (1) a number of limbic-diencephalic structures and pathways are damaged by PTD treatment and may contribute to behavioral impairments; (2) the DO procedure, relative to a nondifferential procedure, enhances the speed of acquisition of MTP in PTD-treated rats; and (3) alternative cognitive mechanisms available to PTD-treated rats permit a level of memory performance comparable to that of normal control rats.

\section{Pathological-Behavioral Relationships}

The present study provides further evidence for a relationship between extensive damage of midline and in-

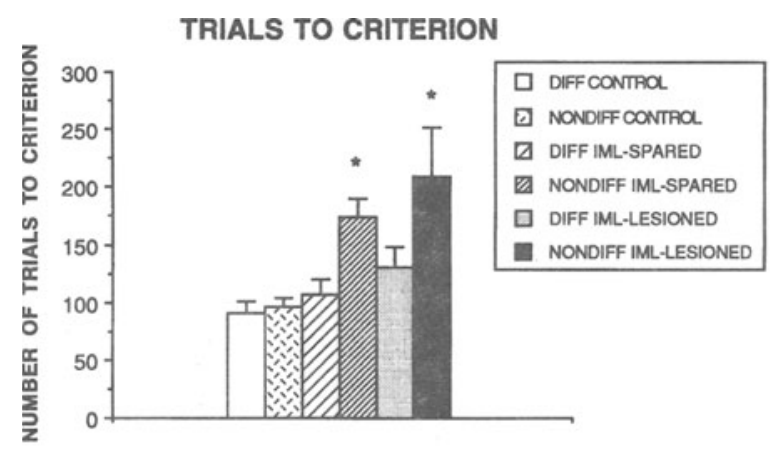

DELAY TRIALS

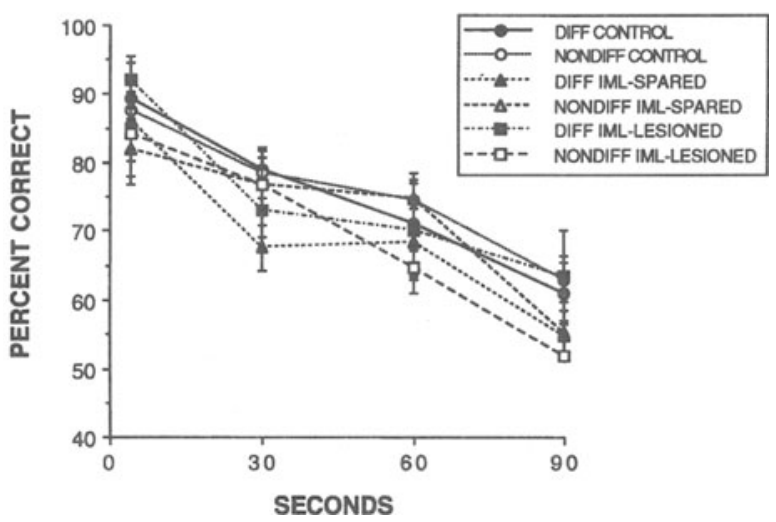

Figure 2. Performance of control, IML-spared, and IML-lesioned groups on acquisition and delayed recall trials of a spatial matchingto-position (MTP) task. Panel A: mean number of trials required to reach criterion during acquisition of MTP. Panel B: mean percent correct during sessions of mixed delayed recall. Asterisks represent a significant difference from control. (Error bars represent $\pm 1 S E M$.)

ternal medullary lamina thalamic regions (IML-lesioned) and behavioral impairments in recovered PTD rats (Langlais et al., 1992; Mair, Knoth, et al., 1991; Mair \& Lacourse, 1992; Mair, Otto, et al., 1991). Both of the IMLlesioned groups in this study had brain damage similar to that observed in many other PTD studies (Mair, Knoth, et al., 1991; Mair, Otto, et al., 1991; Robinson \& Mair, 1992; Langlais \& Savage, 1995), and those trained with the nondifferential procedure, as in previous studies, were greatly impaired on the acquisition MTP.

However, determining exactly what neural structures damaged by PTD treatment are responsible for the learning and memory impairments in the IML-lesioned rats is difficult because a number of structures and pathways in the IML region are implicated in cognitive, motor, and memory processes. Among these are (1) the intralaminar nuclei believed important for arousal and attention (Steriade \& Glen, 1982); (2) afferent projections from anterior ventral to cingulate and mediodorsal to prefrontal implicated in planning, temporal ordering, and discriminative learning (Gabriel, 1993; Markowitsch, 1982); (3) nigro- and cerebellothalamic fibers coursing in the inferior thalamic peduncle and IML (Gerfen, Staines, Ar- 
buthnott, \& Fibiger, 1982; Haroian, Massopust, \& Young, 1981 ) involved in gating sensory-memory information and selection of motor responses (Johnstone \& Rolls, 1990); and (4) hippocampal-thalamic connections coursing through the mammillothalamic tract. Damage to the mammillothalamic tract has been associated with learning and memory deficits in rats (Béracochéa \& Jaffard, 1987; Field, Rosenstock, King, \& Greene, 1978; Thomas \& Gash, 1985). Atrophy of the parietal cortex of the IMLlesioned animals confirms earlier observations (Langlais \& Savage, 1995) and may have also contributed to the observed behavioral impairments by disrupting sensoryperceptual processing.

The learning impairments observed in the IML-spared groups cannot be attributed to IML, mammillary body, or cortical damage because these areas were relatively or totally preserved. Several observations suggest that damage to the anterior nucleus of the thalamus may be responsible for the learning impairments in the IML-spared groups: (1) impaired acquisition of a similar task, NMTP, in PTD rats with anterior ventral damage (Langlais \& Savage, 1995); (2) radio frequency or neurotoxic lesions to the anterior ventral complex that produce behavioral impairment (Aggleton \& Sahgal, 1993; Peinado-Manzano \& Pozo-Garcia, 1991; Sutherland \& Rodriguez, 1989 ); and (3) the connection of the anterior ventral complex to a number of limbic structures involved in memory (Gabriel, Foster, Orona, Saltwick, \& Stanaon, 1980; Shibata, 1993).

These results demonstrate that the pathological damage produced by an acute bout of thiamine deficiency is variable and involves numerous brain structures implicated in cognitive, motor, and memory processes. These behavioral and pathological features are remarkably similar to those found in human WKS (Harper \& Kril, 1993; Troncosos et al., 1981; Victor et al., 1971), and they suggest an additive effect of thalamic damage - that is, the more areas damaged, the greater the impairment.

\section{The Influence of the Differential Outcomes Procedure on PTD-Treated Rats}

Regardless of the amount of brain damage caused by the PTD treatment, the DO procedure greatly improved initial learning, as was reflected in the absence of a significant difference in trials-to-criterion between the DIFF IML-spared, DIFF IML-lesioned groups, and controls. These results, as predicted, suggest that the DO procedure can improve memory performance of amnestic subjects.

However, some findings of the current study do not fit the original hypothesis regarding the influence of the DO procedure. First, although there was a nonsignificant trend, the DIFF control rats did not display enhanced performance relative to the NONDIFF control rats. This lack of effect may be attributed to the dynamics of the Tmaze MTP paradigm. This task is easy for normal rats to learn (criterion in 100 trials), thereby creating a ceiling effect (Rawlins \& Deacon, 1993) that may prevent the detection of the DOE. However, this ceiling effect is nonexistent for PTD-treated rats, because of their slower learning curve. The slower learning curve created a window for improvement and for the detection of the DOE. Previous experiments suggest that the DOE is most prominent when stimulus control is relatively difficult to establish (Goeters et al., 1992).

Another unexpected finding was the lack of a difference in delayed MTP performance between the differential and nondifferential groups. Other studies have shown an enhancement of both acquisition and delayed performance using the DO procedure. Acquisition and delayed performance on this task likely involve different cognitive strategies, and apparently the DO procedure influences only those used to learn this task. An important difference between the T-maze and other delayed conditional discriminations is that the "to-be-remembered item" and the correct choice behavior are the same and involve a response chain rather than a discrete stimulus or response. However, the apparent task-specific effects of the DO procedure demonstrate that the mechanisms contributing to the DOE are not fully understood.

Regardless of the precise mechanism, the present observations demonstrate that additional neural systems, tapped by the DO procedure, are spared in PTD animals and can be used to solve problems of matching. This hypothesis is consistent with the work of many researchers in learning and memory which suggests that different types of information are processed in different, but parallel, structural brain pathways (Cermak, 1993; Cohen, 1984; Mishkin, 1992; Squire, Knowlton, Musen, 1993; Weiskrantz, 1987). What pathway becomes "dominant" is a factor of the paradigm, the modality of incoming information, and the type of association used to solve the task.

The exact mechanisms that are used to solve conditional discriminations with differential outcomes is not known. Recently, DeMarse and Urcuioli (1994) have demonstrated that symbolic MTS acquisition is also enhanced by pairing different outcomes with comparison stimuli instead of sample stimuli. Others have suggested that DOE may be produced by the unique response topography required by the distinct reinforcers, and that different consummatory response requirements may enhance the discriminability of the stimuli in the DO paradigm (Alling et al., 1991 a, 1991b). All these studies suggest that a variety of different associations (samplereinforcer, comparison-reinforcer, response-reinforcer), individually or in conjunction with one another and depending on the task, are responsible for the DOE. Future research in examining the mechanisms of the DOE and the contribution of those mechanisms to enhanced performance in brain-damaged subjects is warranted.

\section{REFERENCES}

Aggleton, J. P., \& Sahgal, A. (1993). The contributions of the anterior thalamic nuclei to anterograde amnesia. Neuropsychologia, 31, 1001-1019.

Alling, K., Nickel, M., \& Poling, A. (1991a). The effects of differential and nondifferential outcomes on response rates and accuracy 
under a delayed-matching-to-sample procedure. Psychological Record, 41, 537-549.

Alling, K., Nickel, M., \& Poling, A. (1991b). The effects of phenobarbital on responding under delayed-matching-to-sample procedures with differential and nondifferential outcomes. Pharmacology, Biochemistry \& Behavior, 39, 817-820.

BÉRACOHÉA, D. J., \& JAFFARD, R. (1987). Impairments of spontaneous alternation behavior in sequential test procedures following mammillary body lesions in mice: Evidence for time-dependent interference-related memory deficits. Behavioral Neuroscience, 2, 187-197.

Carlson, J. G., \& Wielkiewicz, R. M. (1976). Mediators of the effects of magnitude of reinforcement. Learning \& Motivation, 7, 184-196.

CERMAK, L. (1993). Memory deficits in alcoholic Korsakoff patients. In W. A. Hunt \& S. J. Nixon (Eds.), Alcohol-induced brain damage (pp. 121-156). Bethesda, MD: U.S. Department of Health and Human Services.

CoHEN, N. J. (1984). Perserved learning capacity in amnesia: Evidence for multiple memory systems. In L. R. Squire \& N. Butters (Eds.), Neuropsychology of memory (pp. 83-103). New York: Guilford.

Demarse, T. B., \& URCUIOLI, P. J. (1994). Enhancement of matching acquisition by differential comparison-outcome associations. Journal of Experimental Psychology: Animal Behavioral Processess, 19, 317-326.

FedorchaK, P. M., \& Bolles, R. C. (1986). Differential outcomes effect using a biologically neutral outcome difference. Journal of Experimental Psychology: Animal Behavior Processes, 2, 125-130.

FELlows, B. J. (1967). Chance stimulus sequences for discrimination tasks. Psychological Bulletin, 2, 87-92.

Field, T. D., Rosenstock, J., King, E. C., \& Greene, E. (1978). Behavioral role of the mammillary efferent system. Brain Research Bulletin, 3, 451-456.

GABREL, M. (1993). Discriminative avoidance learning: A model system. In B. A. Vogt \& M. Gabriel (Eds.), Neurobiology of cingulate cortex and limbic thalamus: A comprehensive handbook (pp. 478526). Boston: Birkhauser.

Gabriel, M., Foster, K., Orona, E., Saltwick, S. E., \& Stanaon, M (1980). Neuronal activity of cingulate cortex, anteroventral thalamus, in hippocampal formation and discriminative conditioning: Encoding and extraction of the significance of conditioned stimuli. In J. M. Sprague \& A. N. Epstein (Eds.), Progress in psychobiology and physiological psychology (Vol. 9, pp.125-231). New York: Academic Press.

Gerfen, C. R., Staines, W. A., Arbuthnott, G. W., \& Fibiger, H. C. (1982). Crossed connections of the substantia nigra in the rat. Journal of Comparative Neurology, 207, 283-303

Goeters, S., Blakely, E., \& Polling, A. (1992). Differential outcomes effect. Psychological Record, 42, 389-412.

Haroian, A. J., Massopust, L. C., \& Young, P. A. (1981). Cerebellothalamic projections in the rat: An autoradiographic and degeneration study. Journal of Comparative Neurology, 197, 217-236.

HARPER, C. G., \& KrIL, J. J. (1993). Neuropathological changes in alcoholics. In W. A. Hunt \& S. J. Nixon (Eds.), Alcohol-induced brain damage (pp. 39-69). Bethesda, MD: U.S. Department of Health and Human Services.

JACOBSON, R. R., \& Lishman, W. A. (1987). Selective memory loss and global intellectual deficits in alcoholic Korsakoff's syndrome. Psychological Medicine, 17, 649-655.

JaCOBSON, R. R., \& Lishman, W. A. (1990). Cortical and diencephalic lesions in Korsakoff's syndrome: A clinical and CT scan study. Psychological Medicine, 20, 63-75.

Johnstone, S., \& Rolls, E. T. (1990). Delay, discriminatory, and modality specific neurons in striatum and pallidum during shortterm memory tasks. Brain Research, 522, 147-151.

LANGLAIS, P. J. (1992). Role of diencephalic lesions and thiamine deficiency in Korsakoff's amnesia: Insights from animal models. In L. R. Squire \& N. Butters (Eds.), Neuropsychology of memory (pp. 440-450). New York: Guilford.

Langlais, P. J., \& MaIR, R. G. (1990). Protective effects of the glutamate antagonist MK-801 on pyrithiamine-induced lesions and amino acid changes in rat brain. Journal of Neuroscience, 10, 1664 1674.

Langlais, P. J., Mandel, R. J., \& Mair, R. G. (1992). Diencephalic le- sions, learning impairments and intact retrograde memory following acute thiamine deficiency in the rat. Behavioral Brain Research, 48, 177-185.

Langlais, P. J., \& Savage, L. M. (1995). Thiamine deficiency in rats produces cognitive and memory deficits on spatial tasks that correlate with tissue loss in diencephalon, cortex and white matter. $B e$ havioral Brain Research, 68, 75-89.

LANGLAIS, P. J., \& ZHANG, S.-X. (1993). Extracellular glutamate is increased in thalamus during thiamine deficiency-induced lesions and is blocked by MK-801. Journal of Neurochemistry, 61, 2175-2182. Linwick, D., Overmier, J., Peterson, G., \& Mertens, M. (1988). Interaction of memories and expectancies as mediators of choice behavior. American Journal of Psychology, 101, 313-334.

Mair, R. G., Anderson, C. D., Langlais, P. J., \& McEntee, W. J. (1985). Thiamine deficiency depletes cortical norepinephrine and impairs learning processes in the rat. Brain Research, 360, 273-284.

Mair, R. G., KNOTh, R. L., Rabchenuk, S. A., \& Langlais, P. J. (1991). Impairment of olfactory, auditory, and spatial serial reversal learning in rats recovered from pyrithiamine-induced thiamine deficiency. Behavioral Neuroscience, 105, 360-374.

MAIR, R. G., \& LACOURSE, D. M. (1992). Radio-frequency lesions of the thalamus produce delayed-nonmatching-to-sample impairments comparable to pyrithiamine-induced encephalopathy in rats. Behavioral Neuroscience, 106, 634-645.

Mair, R. G., Otto, T. A., Knoth, R. L., Rabchenuk, S. A., \& LANGLAIS, P. J. (1991). Analysis of aversively conditioned learning and memory in rats recovered from pyrithiamine-induced thiamine deficiency. Behavioral Neuroscience, 105, 351-359.

MARKowitsCH, H. J. (1982). Thalamic mediodorsal nucleus and memory: A critical evaluation of studies in animals and man. Neuroscience \& Biobehavioral Reviews, 6, 351-380.

Mishkin, M. (1992). Neural circuitry underlying behavioral deficits in aging. Neurobiology of Aging, 14, 615-617.

PARSON, O. A., \& NixON, S. J. (1993). Neurobehavioral sequelae of alcoholism. Behavioral Neurology, 11, 205-218.

PAXINos, G., \& WATSON, C. (1986). The rat brain in stereotaxic coordinates. San Diego: Academic Press.

Peterson, G., \& Trapold, M. (1980). Effects of altering outcome expectancies on pigeons' delayed conditional discrimination performance. Learning \& Motivation, 11, 267-288.

Peinado-Manzano, M. A., \& Pozo-Garcia, R. (1991). The role of different nuclei of the thalamus in processing episodic information. Behavioural Brain Research, 45, 17-27.

RaWLins, J. N. P., \& DEACON, R. M. J. (1993). Further developments of maze procedures. In A. Sahgal (Ed.), Behavioral neuroscience: $A$ practical approach (pp. 123-136). New York: IRL Press, Oxford University Press.

RoBinson, J. K., \& MAIR, R. G. (1992). MK-801 prevents brain lesions and delayed-nonmatching-to-sample deficits produced by pyrithiamine-induced encephalopathy in rats. Behavioral Neuroscience, $106,622-623$.

Savage, L. M., Stanchileld, M. A., \& Overmier, J. B. (1994). The effects of scopolamine, diazepam and lorazepam on working memory in pigeons: An analysis of reinforcement procedures and sample problem type. Pharmacology, Biochemistry \& Behavior, 48, 183192.

Shibata, H. (1993). Direct projections from the anterior thalamic nuclei to the retrohippocampal region in the rat. Journal of Comparative Neurology, 337, 431-445.

SQuire, L. R., KNOWLton, B., \& MUSEN, G. (1993). The structure and organization of memory. Annual Review of Psychology, 44, 453485.

Steriade, M., \& GlenN, L. L. (1982). Neocortical and caudate projection of intralaminar thalamic neurons and their synaptic excitation from midbrain reticular core. Journal of Neurophysiology, 48 , 352-372.

Sutherland, R. J., \& Rodriguez, A. J. (1989). The role of the fornix/fimbria and some related subcortical structures in place learning and memory. Behavioural Brain Research, 32, 265-277.

Thomas, G. J., \& GaSh, D. M. (1985). Mammillothalamic tracts and representational memory. Behavioral Neuroscience, 99, 621-630.

ThOMAS, G. J., \& SPAFFoRd, P. S. (1984). Deficits for representational 
memory induced by septal and cortical lesions (singly and combined) in rats. Behavioral Neuroscience, 98, 394-404.

TRAPOLD, M. A. (1970). Are expectancies based upon different positive reinforcing events discriminably different? Learning \& Motivation, 1, $129-140$.

Troncoso, J. C., Johnston, M. V., Hess, K. M., Griffin, J. W., \& PRICE, D. L. (1981). Model of Wernicke's encephalopathy. Archives of Neurology, 38, 350-354.

Victor, M., ADAMS, R. D., \& Collins, G. H. (1971). The WernickeKorsakoff syndrome. Philadelphia: F. A. Davis.
WEISKRaNZ, L. (1987). Neuroanatomy of memory and amnesia: A case for multiple memory systems. Human Neurobiology, 6, 93-105. Williams, D. A., Butler, M. M., \& Overmier, J. B. (1990). Expectancies of reinforcer location and quality as cues for a conditional discrimination in pigeons. Journal of Experimental Psychology: Animal Behavioral Processes, 16, 3-13.

(Manuscript received November 16, 1994; revision accepted for publication January 31, 1995.) 